\title{
DIVERSIDADE, SOCIABILIDADE E SUPERIORIDADE MASCULINA NO COTIDIANO DA RUA ${ }^{1}$
}

\author{
Fábio Santos de Andrade \\ Universidade Federal de Rondônia - UNIR \\ Grupo Humanize
}

\section{CONSIDERAÇÕES INICIAIS}

Historicamente, crianças e adolescentes em situação de rua sempre foram vítimas inquestionáveis de atos de violência. Atualmente, mesmo vivendo um novo tempo em que o pensar sobre a criança e o adolescente ganha respaldo legal, em carater de prioridade absoluta nos cuidados por parte do Estado e da sociedade, ainda convivemos com a violência gratuita que os colocam em situação de alerta constante. Para além da violência, o novo contexto também tem fortalecido o desejo humano de vivenciar um novo mundo em que o respeito à criança e ao adolescente se materialize em uma nova vida pautada na humanização e na justiça social.

Para nós, pesquisadores e pesquisadoras, viver e pesquisar o cotidiano das crianças e adolescentes em situação de rua envolve a trilha de um caminho onde, segundo Pais (2003, p. 29), é preciso passar um pente fino "[...] procurando os significantes mais do que significados, juntando-os como quem junta pequenas peças de sentido num sentido mais amplo". Assim, para compreender a rua dos meninos e meninas é preciso vivenciar seu mundo invisível e não apenas visitá-lo. A rua das crianças e adolescentes,

É uma rua invisível para a maioria da população que por ela circula [...]. Os que vivem na rua, nela constroem as relações definidoras de suas existências. Redefinem o espaço, erguem paredes invisíveis, numa partilha minuciosa dos locais. (CRIADY, 1998, p. 21)

Nas ruas, crianças e adolescentes sempre foram obrigados a buscar sua sobrevivência enfrentando desafios que os impulsionam a desenvolver táticas de sobrevivência que nosso olhar, enquanto coletividade influenciada por questões culturais e históricas, se desloca, constantemente, para o campo do lícito ou do ilícito. Nesse contexto, rótulos passam a ter significado e identificação, as crianças e adolescentes perdem seus nomes e passam a ser chamados de menor, menino de rua, marginal, coitadinho, pivete, trombadinha, bandido, excluído, dentre outros.

${ }^{1}$ DOI 10.29388/978-65-86678-76-5-f.123-138 
Nas relações se sociabilidade entre meninos e meninas, para além da pobreza, também se manifesta um machismo culturalmente enraizado nas vivências, onde meninas e mulheres são subordinadas e submetidas a crueldades tidas como normais. De acordo com Bonetti (2011, p. 94), "O sistema de valores de gênero e sexualidade na nossa sociedade atribui um valor negativo menor àquilo que é considerado feminino, criando discriminação contra as mulheres". Nessa trilha, decidimos tratar, nesse texto, sobre diversidade, sociabilidade e superioridade masculina no cotidiano da rua.

\section{CUIDADOS NA PESQUISA COM CRIANÇAS E ADOLESCENTES EM SITUAÇÃO DE RUA}

Ao nos debruçarmos sobre as literaturas, documentos e relatórios que tratam da criança e do adolescente em situação de rua, deparamo-nos com o olhar e o lugar de fala dos(as) pesquisadores(as). Os textos trazem em seu conteúdo os sonhos, as inquietações, os conceitos e os preconceitos que os(as) autores(as) transportam para a escrita. Em muitos casos, a descrição das crianças e adolescentes em situação de rua possuem muito mais o que o olhar do pesquisador captou (carregado de conceitos e preconceitos) do que o que realmente elas são em essência.

Essa é uma questão que sempre nos inquietou, trazendo questionamentos sobre a real possibilidade de dispor no texto as falas das crianças e adolescentes em situação de rua sem ter uma escrita carregada apenas de significados. Assim, o como entrar no mundo das crianças e adolescentes fala muito sobre o como sair positivamente sem violentá-las. Sabemos que entrar no mundo envolve um campo de subjetividades que questiona, a todo momento, o lugar de fala do(a) pesquisador(a). Ir à rua e tentar fugir dos vícios culturais e ideológicos é sempre um grande desafio para a pesquisa.

A maioria das experiências vivenciadas na rua são imperceptíveis para os que não compreendem as paredes invisíveis que se erguem, guardando um mundo que é vivenciado pelos que estão em situação de rua. Nossa vida cotidiana, nossa conveniência, tornou a rua um símbolo de passagem e as pessoas em situação de rua são normatizadas como parte dos espaços públicos. Assim, tornar visível o invisível é uma tarefa que envolve o exercício contínuo de tentar perceber o mundo a partir de sua essência e de sua diversidade.

[...] qualquer definição de mundo seria apenas uma caracterização abstrata que nada nos diria se já não tivéssemos acesso ao definido, se não o conhecêssemos pelo único fato de que somos. É na experiência de mundo que todas as nossas operações lógi- 
cas de significação devem fundar-se, e o próprio mundo não é, portanto, uma certa significação comum a todas as nossas experiências, que leríamos através delas, uma ideia que viria animar a matéria do conhecimento (MERLEAU-PONTY, 2011, p. 440).

Nesse contexto, as crianças e adolescentes em situação de rua perdem sua humanidade, seus direitos sociais e passam a sobreviver da pena, da repulsa, do medo, da caridade e da violência. Passam, no imaginário popular, a pertencer à rua, sendo identificadas por seus locais de permanência que se tornam seus sobrenomes: "João da praça..., Maria da rua..., Pedro do semáforo..., Ana da esquina... etc". Ressignificar nossa percepção sobre a rua nos possibilita enxergar o invisível. Para Paulo Freire (2000. p. 33), não estamos no mundo para simplesmente nos adaptarmos a ele, mas para transformá-lo, e para isso devemos usar toda possibilidade que temos para não apenas falar de utopia, mas participar de práticas coerentes. São essas reflexões que conduziram nossas pesquisas e deram forma a esse trabalho.

Para a construção desse texto decidimos apresentar dados de encontros e pesquisas com as crianças e adolescentes em situação de rua, realizados entre 1999 e 2019, na cidade de Vitória da Conquista (BA). Cabe destacar que os resultados apresentados são frutos do que a memória pode capturar, pois estar na rua (como educador e pesquisador) significa respeitar o vínculo de confiança estabelecido, transformando os diálogos em momentos prazerosos sem a formalidade do gravar, anotar e filmar. Todas as notas foram feitas em casa a partir do que a memória conseguiu guardar. Para Jenkins (2007, p. 31), "[...] nenhum historiador consegue abarcar e assim recuperar a totalidade dos acontecimentos passados, porque o "conteúdo" desses acontecimentos é praticamente limitado". Ao visitar a história consideramos o pensamento de Merleau-Ponty (2006, p. 02):

O historiador não pode passar os olhos pelo passado sem lhe dar sentido, sem pôr nele o relevo do importante e do acessório, do essencial e do acidental, dos esboços e das realizações, das preparações e das decadências, e esses vetores, traçados sobre o conjunto compacto dos fatos, já desfiguram um real onde tudo é igualmente real e cristalizam nele nossos interesses.

Durante as pesquisas, o contato com as crianças e adolescentes sempre aconteceu em duas fases. A primeira, a fase da "paquera", foi o momento dos primeiros contatos que objetivavam despertar a curiosidade sobre o que realizávamos. Foi o tempo das apresentações, das várias perguntas; o momento de criação dos primeiros vínculos, mesmo que frágeis, de conhecer seus parceiros e desafetos e de observar sua rotina. Foi 
o momento de acolhida ao educador/pesquisador nos espaços onde as táticas de sobrevivência se desenvolvem. A segunda fase, "namoro", foi o momento de aprofundar o diálogo. Esse era o momento em que a criança ou o adolescente já não via mais o pesquisador como um estranho e podia falar sobre suas vidas sem se preocupar com qualquer julgamento ou denúncia pois o vínculo de confiança já estava estabelecido.

É importante destacar que durante as pesquisas não oferecemos qualquer bem material, dinheiro ou alimento, para as crianças e adolescentes. Queríamos que o pesquisador fosse visto como um participante do mundo deles e não como alvo para suas táticas de sobrevivência.

\section{MENINOS, MENINAS: SUBJETIVIDADES E RELAÇÕES DE PODER}

Não podemos generalizar, afirmando que todas as crianças e adolescentes em situação de rua vivem ou dormem nas ruas, podemos afirmar que todas sobrevivem das ruas. Muitas, devido aos fortes vínculos familiares, às diversas recomendações de seus responsáveis ou ao fato de estarem nas ruas acompanhados da família, conseguem retornar para suas casas. Contudo, a rua ainda continua a exercer forte atrativo, ainda que pese a violência nela gerada. É na rua que os atos para a sobrevivência individual ou coletiva se manifestam de forma lícita ou ilícita. São esses atos que denominamos com táticas de sobrevivência.

Normalmente, as táticas de sobrevivência, também denominadas como "viração", "caça jeito", "correria", "mangueamento" e "desenrascaço", exigem uma convivência grupal entre os usuários do espaço urbano, o que possibilita a otimização do seu tempo e promove a eficácia da ação executada por eles.

Para sobreviver, as crianças e adolescentes em situação de rua estão distribuídas em diversos grupos que possuem características próprias e regras de convivência e sobrevivência influenciadas pelo tempo e espaço. Dentre os diversos grupos Andrade (2019, p. 87 - Grifos do autor) destaca cinco:

1. Crianças e adolescentes que mantêm vínculo com a família e com a escola - Os membros deste grupo mantêm fortes vínculos familiares, tem residência fixa e frequentam a escola. Vão à rua desenvolver táticas de sobrevivência, no turno oposto ao da escola, a fim de geraram renda para contribuir no sustento da família. Em muitos casos o rendimento escolar é baixo, tendo em vista que as táticas de sobrevivência provocam o esgotamento físico e mental, o que, consequentemente, interfere na execução das atividades escolares; 
2. Crianças e adolescentes que mantêm vínculo com a família e que abandonaram a escola - Os membros deste grupo mantêm fortes vínculos familiares e tem residência fixa, no entanto, deixaram a escola, priorizando a ida à rua, na tentativa de garantir a sobrevivência individual e familiar. Desenvolvem táticas de sobrevivência na rua e retornam para casa ao final do dia levando os ganhos que complementam o sustento da família;

3. Crianças e adolescentes que vão à rua acompanhados da família - Esse grupo vai à rua em família e retorna para casa ao fim do dia. Normalmente é composto, principalmente, por pais e filhos e as táticas de sobrevivência são desenvolvidas em grupo, destacando especialmente a mendicância;

4. Crianças e adolescentes que tomaram a rua como moradia, mas ainda mantêm vínculos familiares - Esse grupo passou a residir na rua, mas ainda mantêm vínculos com as famílias, que tem residência fixa, visitando-as regularmente. Em muitos casos, as famílias residem em cidades diferentes das que as crianças e adolescentes em situação de rua estão;

5. Crianças e adolescentes que perderam os vínculos familiares, tomando a rua como moradia - Esse grupo é formado por crianças e adolescentes independentes. Os laços familiares foram rompidos por diversos fatores (distância, brigas, exploração, abusos, falta de comida etc.). Vivem em grupos que delimitam espaços, regras de convivência e funções na rua. Desenvolvem táticas de sobrevivências diversas: roubo, mendicância, malabares, uso e venda de drogas, relações sexuais consentidas ou pagas. Muitos formam famílias e têm filhos, mesmo morando na rua. Há casos em que bebês são alugados, para serem usados como sensibilizadores na mendicância, fazendo-se passar por pais da criança. Assim, para eles, a rua se torna um lugar de dinâmicas variadas.

Nesses contextos, a vida grupal na rua é construída gradativamente a partir do reconhecimento, da posse dos espaços e dos laços de sociabilidade. Gradativamente também se dá o afastamento da família, onde os vínculos vão diminuído e as visitas à casa se tonam cada vez menos frequentes. A vida na rua passa a ser suleada por novas regras e códigos morais e éticos que atuam como princípios de convivência. Em contraponto, a vida em sociedade, mesmo na rua, pressupõe a limitação da liberdade individual, pois, a partir do momento em que as crianças e adolescentes vivem em grupo, os seus desejos e princípios se tornam coletivos e elas passam a conviver sob normas de conduta que as condicionam a agir moderadamente. 
Muitas regras e códigos que deveriam proporcionar uma melhor convivência, dependem, para a sua execução, da posse de bens materiais e culturais por parte dessas crianças e adolescentes. Para elas, seguir as regras e códigos é, muitas vezes, condenar-se à morte devido à falta de garantia de condições básicas de sobrevivência por parte do Estado. Isso faz com que esse grupo crie novos códigos e regras, levando em consideração as necessidades da vida cotidiana e as peculiaridades do mundo construído na rua. Nesse campo, o ilícito e a violência tomam forma e podem garantir a sobrevivência.

A rua também possibilita que cada criança ou adolescente se identifique com seus pares provenientes do mesmo universo de miséria e que buscam ali sua sobrevivência, formando grupos onde brincam, trabalham, namoram e sobrevivem. Em suma, a vida coletiva da rua começa a substituir os vínculos familiares. De acordo com Gregori (2000, p. 67), o rompimento dos vínculos familiares possibilita a composição de outros laços "[...] agora com o universo das ruas e, em particular, com as turmas que nelas são formadas". Assim, complementa a autora, "[...] a infância e a família são substituídas pelos grupos de pares nas ruas" Gregori (2000, p. 67).

De acordo com Feffermann (2006, p. 177), os jovens se agrupam por identificação, "Mas se, num primeiro momento, essa é a finalidade, percebe-se que muitos destes grupos transformam-se e passam a ter como propósito, implícito ou explícito, a manutenção das condições sociais". Esses grupos passam a ter o sentido de família cuidadora e protetora.

A rua só presta se você souber cair nela, se souber lutar, viver, como por exemplo, quando eu caí na rua eu não tinha amizade, eu não conhecia ninguém. Agora a gente é unido assim, se eu consigo uma coisa todo mundo vai comer. Se um tem um dinheiro assim, eles compra um negócio pra todo mundo. Se come e fica de marra a gente não deixa, todo mundo é irmãozinho. (LEITE, 2001, p. 168)

Mas, além da proteção, os grupos carregam vícios culturais que muitas vezes se manifestam em atos de violência.

Nesta perspectiva, a violência pode ocorrer nas relações sociais as mais diversas, sendo que o próprio reconhecimento das diferenças entre sujeitos e grupos, que se manifesta na construção das identidades e alteridades, pode constituir-se em fonte de tensão latente ou manifesta. Ao transformar a diferença em assimetria,

\footnotetext{
${ }^{2}$ Trecho extraído de uma entrevista feita com um adolescente de 15 anos de idade que se encontrava em situação de rua na cidade do Rio de Janeiro, no final da década de 1990. Publicado por Leite (2001, p. 168).
} 
numa relação hierárquica de desigualdade com fins de dominação, de exploração e opressão [...]. (CHAUÍ, 1984, p.51)

É nessa trilha que a violência assume diversas formas, se manifestando nas relações de sociabilidade dos meninos e meninas em forma de machismo consciente e inconsciente, de exploração sexual e de dominação do corpo.

\section{MACHISMO E SUPERIORIDADE MASCULINA}

A maioria das crianças e adolescentes que estão em situação de rua deixaram suas casas por motivos similares, como pobreza e violência doméstica. Nos casos onde há violência, a figura masculina (representada pelo pai, irmão, padrasto, tio e avô) sempre ganha destaque autoritário e machista, enquanto a figura feminina (representada pela mãe, madrasta, irmã, avó e tia) sempre ocupa um lugar de subordinação. Para Swain (2011, p. 86), o sistema patriarcal criou,

[...] um processo de diferenciação sexual, ligado à expressão do "natural". Ser homem, neste sistema, passa a ser sinônimo de razão, criação, autoridade, poder, e ser mulher, limitada a seu destino biológico, significa ser mãe, esposa, dedicada, cuidando de todos, das crianças, dos velhos, das famílias e dos doentes. Ou, caso recuse estas funções, ela passa a ser considerada prostituta, ou "histérica", ou autoritária, ou masculinizada.

É no sistema patriarcal, que supervaloriza a figura masculina, que o machismo ganha força e se manifesta em atos de violências contra o feminino. Assim,

O machismo pode ser definido como um conjunto de crenças, atitudes e condutas que repousam sobre duas ideias básicas: por um lado, a polarização dos sexos, isto é, uma contraposição do masculino e do feminino segundo a qual são não apenas diferentes, mas mutuamente excludentes; por outro, a superioridade do masculino nas áreas que os homens consideram importantes. Assim, o machismo engloba uma série de definições sobre o que significa ser homem e ser mulher, bem como toda uma forma de vida baseada nele. (CASTAÑEDA, 2006, p. 16).

Na rua, essa prática se manifesta nas relações de sociabilidade onde os meninos ganham status de superioridade, inferiorizando as meninas. Para dar forma às reflexões apresentamos recortes das pesquisas realizadas, evidenciamos o machismo presente nas relações de sociabilidade. Tendo em vista que a identificação das crianças e adolescentes pode comprometer sua segurança e ferir o Estatuto da Criança e do Adolescen- 
te - ECA (BRASIL, 1990), no momento em que os(as) expõe, optamos pela utilização de nomes fictícios.

\section{AS RELAÇÕES FAMILIARES}

Eu moro com minha tia, meus pais morreram já. Eu tenho dois irmãos que moram no Rio. Minha irmã tem casa própria já. Meu irmão mora com minha irmã. Já morei no Rio, lá num deu muito certo não, aí eu vim pra qui. Aqui a convivência com minha tia é boa, eu me entendo com ela (ANDRADE, 2008, p. 83)

O relato pertence a João 3 é um dentre vários narrados pelas crianças e adolescentes em situação de rua. No caso de João, a boa relação com tia não o impediu de ir para rua. A pobreza impulsionou sua saída de casa em busca de recursos que contribuíssem com a renda familiar e nesse aspecto o ser masculino o tornou responsável pala renda familiar, abandonando as atividades próprias de sua idade, incorporando a figura do "homem adulto responsável".

Outro caso interessante é de o Flor $^{4}$ (ANDRADE, 2014, p. 138) que, mesmo não estando em situação efetiva de rua, vivenciava a entrega de sua mãe à superioridade masculina. Aos domingos a mãe de Flor ia a um bar, localizado na feira, para beber com alguns homens que ali se reuniam. Uma situação que Ihe permitia beber de graça e, em troca, se entregar às caricias e toques masculinos. Por não ter com quem deixar a filha, ela a levava para a feira. Enquanto sua mãe ficava no bar, Flor mendigava, situação que, na época, nos chamou muito a atenção e fez com que a escolhêssemos para a pesquisa.

Flor via com normalidade a situação em que sua mãe se encontrava, pois ali também estavam outras mulheres vivenciando as mesmas práticas e ela sempre conviveu com essa realidade e sem a presença de uma figura paterna. Flor também recebia mimos dos homens que estavam com sua mãe e não via como negativa a relação estabelecida entre eles. Flor gostava de ver sua mãe como centro das atenções e via as relações machistas como benéficas para as duas, externalizando o desejo de viver algo parecido.

${ }^{3}$ Os dados foram levantados durante o ano de 2007, na cidade de Vitória da Conquista (BA). Na época, João tinha 14 anos.

${ }^{4}$ Os dados foram levantados durante o ano de 2014, na cidade de Vitória da Conquista (BA). Na época, Flor tinha 12 anos. 


\section{O MENINO E A INCORPORAÇÃO DO MACHISMO}

Caso importante a ser relatado é o de $\operatorname{Marcos}^{5}$ (ANDRADE, 2014, p. 86), um adolescente, que durante a semana trabalhava como servente de pedreiro, ajudando o pai em construções, e no sábado ia ao mercado trabalhar carregando feiras. Todo o dinheiro que ganhava era para ajudar sua família e para gastos pessoais com roupas, festas e alimentação. Seu pai dizia que ele deveria trabalhar se quisesse ter dinheiro para sair com amigos e comprar as coisas de que precisa. Dizia também que ele era homem e precisa se comportar com tal, assumir responsabilidades e ganhar seu próprio dinheiro.

Como a rotina do mercado começa muito cedo, Marcos saia de casa por volta das $03 \mathrm{~h} 30$ da manhã do sábado e chegava ao mercado às 04h30. Chegava sempre cedo para transportar as mercadorias dos comerciantes, entre o local de desembarque e o ponto de comércio, ganhando, em média, 2,00 reais por transporte. Após as $07 \mathrm{~h} 00$, começava o transporte de compras dos clientes e após o meio dia, quando termina a feira, recomeçava o trabalho com os comerciantes. Todo esse trabalho lhe rende em média 30,00 reais por dia. Para ele, manter essa rotina era garantir clientes certos. "Muitas vezes eu não preciso ficar correndo atrás de carrego, já tenho pessoas certas que me procuram todo sábado. Só vou atrás de outro carrego no tempo que estou livre" (ANDRADE, 2008, p. 86), afirma Marcos.

$\mathrm{O}$ trabalho no mercado tinha momentos bons e ruins. O encontro com amigos, os momentos de descontração eram muito importantes. Quando estacionava a galeota em seu ponto fixo, onde esperava ser chamado por seus clientes, ele interagia com os outros carregadores, esse era o momento de brincadeira, de "zoação". Orgulhava-se das amizades que fazia na feira, assim conseguia comprar muitas coisas com desconto e às vezes ainda levava para casa produtos, como frutas e verduras, que eram doados pelos comerciantes após o término dos trabalhos.

$O$ ruim para ele era o cansaço, às vezes tinha que transportar cargas muito pesadas, o que Ihe provocava dores musculares. Quando era dia chuvoso ficava muito difícil locomover a galeota pesada e às vezes acabava se machucando, foi numa situação como essa que perdeu seu chinelo. Também era ruim quando a galeota quebrava e precisava de conserto, pois isso lhe impedia de atender aos clientes e ganhar dinheiro. Às vezes ela quebrava durante o transporte de alguma mercadoria e ele tinha que transportar na mão ou passar o carrego para outra pessoa, o que significa a perda do dinheiro.

${ }^{5}$ Os dados foram levantados durante o ano de 2008, na cidade de Vitória da Conquista (BA). Na época, Marcos tinha 14 anos. 
Para Marcos, o que vivia era normal, pois já se considerava um homem e não podia perder tempo com brincadeiras de criança. Para ele, homem tem que ser responsável, trabalhador e ter condições de sustentar uma família.

\section{A MENINA E O VALOR DO CORPO}

Nas relações sexuais, as meninas em situação de rua sempre são o alvo das disputas. As brigas pela conquista das meninas, crianças ou adolescentes, acontecem cotidianamente. Elas são disputadas como troféu e o "vencedor" tem o direito de tentar conquistá-la. Se for bem sucedido, ganha o respeito do grupo que não interfere no relacionamento e ele pode explorar sexualmente a menina que passa a ser "sua". No entanto, seu sucesso só acontece com a permissão da escolhida que, normalmente, respeita o resultado da disputa, vencida pelo mais forte do grupo. Nessa trilha, Lucas 6 . relata:

Assim, quando a pessoa, quando um menino ficava com uma menina, aí os outro respeitava, num ficava assim sabe, com ousadia não pro lado da menina não, eles respeitava. Aí a pessoa ficava. Aí quando a pessoa num ficava mais com a menina, outra pessoa nova chegava e ficava com ela. (ANDRADE, 2008, p. 100).

As relações sexuais entre os grupos que estão em situação de rua são intensas, onde adultos, crianças e adolescentes, de ambos os sexos, mantêm relações sem distinção de idade e muitas vezes sem nenhum tipo de proteção, ficando vulneráveis às doenças sexualmente transmissíveis.

A noite também reserva momentos de descontração e perigo. Conta Gustavo ${ }^{7}$ (ANDRADE, 2014, p. 132), que a noite é muito boa, eles se reúnem em grupo, bebem, usam as drogas e cantam bastante. Gustavo diz que algumas pessoas que estavam em situação de rua ficaram doentes e até morreram, "Uns disseram que foi por causa da AIDS", mas ele não sabe afirmar. Fato parecido é relatado por Lucas:

Quando encontrava assim, elas ficava mais a gente e sempre tinha essa briga assim pra ver quem ficava com a menina. Aí sempre tinha relações assim meia arriscada e quando elas engravidava elas, perdia o filho porque elas usava droga. (ANDRADE, 2008, p. 99).

\footnotetext{
${ }^{6}$ Os dados foram levantados durante o ano de 2007, na cidade de Vitória da Conquista (BA). Na época, Lucas tinha 17 anos.

${ }^{7}$ Os dados foram levantados durante o ano de 2013, na cidade de Vitória da Conquista (BA). Na época, Gustavo tinha 16 anos.
} 
Ainda segundo Lucas, de vez em quando, à noite, aparecem algumas mulheres, "novinha ou velha. Não é sempre que tem, mas às vezes aparece. Ela vêm sempre para usar drogas, porque mulher não paga" (ANDRADE, 2008, p. 99). Sob os cobertores, as mulheres mantêm relações sexuais com adultos, adolescentes e crianças. "Muitas vezes elas só trocam de cobertor, deixam um e transam com outro. Usam camisinha quando tem, só não perdem é a oportunidade de transar". A entrega do corpo é uma tática de sobrevivência onde meninas podem ter acesso às drogas e principalmente para se sentirem protegidas. Paulo ${ }^{8}$, ao comparar meninos e meninas, afirma que "As meninas são muito diferentes, se alguém oferece thinner para elas, elas deita e já fica muito doida e começa oferecer outras coisas, fica querendo dá". Nesse contexto, o sexo passa a ser a principal "moeda de troca" (ANDRADE, 2008, p. 99), sempre aceita pelos homens.

Essa submissão feminina ao masculino também impõe regras na realização de atividades. Segundo Lucas, "Elas desenvolvem atividades também, mas existe diferença, porque nós os homens é mais ágil, mais rápido, principalmente pra roubar. Assim elas não, fica mais pedindo, é difícil roubar" (ANDRADE, 2008, p. 99).

Mesmo com as afirmações de que as meninas ajudam na aquisição de dinheiro, principalmente por meio da mendicância, de acordo com Gregori (2000, p. 129), "As meninas não são protegidas ou poupadas na dinâmica do cotidiano. [...] Contudo, existem tarefas que apenas as meninas realizam - como lavar roupa ou cuidar dos menores". Isso marca a diferença entre masculino e feminino no grupo, onde a menina sempre estará em uma posição de subordinação.

\section{O PARTO E O DESAPEGO}

Na rua, é comum encontrar adolescentes e pessoas adultas gestando crianças em situações sub-humanas. Essas crianças, quando não são abortadas, são geradas na precariedade da rua e depois cedidas para adoção ou apreendidas pelo Conselho Tutelar que as encaminha ao Juizado da Infância e da Juventude. Este, posteriormente, as encaminha aos familiares dos pais ou para adoção. Relata João:

Tem, a maioria de garota assim que tem filho elas dão, dá mais pra esse povo assim, que tem dinheiro, ai eles dá pra esse povo que tem condição de criar. Tem gente que tá na rua que usa droga aí num quer que o filho, assim, quando crescer usa droga também, num quer não, aí eles pega e prefere dá pra uma pessoa que possa

${ }^{8}$ Os dados foram levantados durante o ano de 2007, na cidade de Vitória da Conquista (BA). Na época, Paulo tinha 13 anos. 
ter cuidado, carinho com a criança. (ANDRADE, 2008, p. 100).

As crianças que conseguem permanecer com as mães são normalmente utilizadas como recurso para mendicância ou são alugadas para outras mulheres que as utilizam nesta prática . "Eu já vi muitas que utilizam criança pra pedir, não era filho dela, era filho de outra" (ANDRADE, 2008 , p. 100), afirma Lucas.

Muitas ganha dinheiro por causa disso, pega o filho, vai pedir, fala que é pra comprar leite, fala que vai comprar o leite, mas, na realidade, nem compra leite nem nada, é tudo pra comprar droga. A criança fica em situação de risco também (ANDRADE, 2008, p. 99).

Neste universo, as adolescentes incorporam a figura da mãe que necessita manter a sobrevivência de sua prole. É esta imagem que tentam passar para seus fregueses ${ }^{9}$, no intuito de conseguir esmolas.

A exemplo temos o caso de Maria ${ }^{10}$, que até os dias de hoje permanece nas ruas de Vitória da Conquista. Iniciamos o acompanhamento de Maria no ano 2000, quando já estava em situação de rua, e nos anos seguintes ela teve 5 filhos, todos entregues para a adoção. Cada um dos filhos foi fruto de um relacionamento diferente e o consumo frequente de drogas e falta do uso de preservativos possibilitou as gestações indesejadas em situações de risco. Numa relação de submissão aos homens com quem se envolvia, Maria usava as gestações como forma de conseguir dinheiro e comida, o que mantinha o sustento dela e de seu companheiro. Após o parto ela ainda usava o bebê como forma de sensibilização e posteriormente entregava para adoção. A situação vivenciada por Maria pode ser identificada em muitas adolescentes em situação de rua, em várias cidades brasileiras.

\section{POR FIM...}

É importante destacar que o cotidiano da rua exerce grande influência na vida das crianças e adolescentes, o que faz com que muitas famílias pobres, residentes em regiões periféricas, não consigam mantê-las em seus bairros, que não oferecem espaços de lazer adequados ou qualquer outro atrativo; tampouco em suas casas, em decorrência, principalmente, da pobreza e da violência familiar.

Essas famílias tem configurações diversas sendo formadas por pais e mães, madrastas ou padrastos, irmãos e irmãs, tios e tias, avós e

\footnotetext{
${ }^{9}$ Denominação dada pelas crianças e adolescentes que estão em situação de rua a todos os que lhes fornece dinheiro, alimento ou objetos.

${ }^{10}$ Os dados foram levantados durante o ano de 2000, na cidade de Vitória da Conquista (BA). Na época, Maria tinha 14 anos.
} 
avôs. Segundo Kosminsky (1993, p. 164), a figura do pai ou padrasto, normalmente, é inconstante na ligação com os jovens, "[...] ao contrário das mães, presença fundamental e decisiva na vida dos filhos". São, muitas vezes, as escolhas conjugais da mãe que provocam o afastamento do filho. Com isso, tal realidade impulsiona cada vez mais as crianças e adolescentes a estarem em situação de rua.

É notório que a rua exerce um encanto aos que dela sobrevivem. As crianças e adolescentes visualizam a rua como um espaço de liberdade, de conquistas, mas o lado perverso se manifesta cotidianamente. Estar em situação de rua significa estar atento às diversas formas de violência. Cada fala supracitada revela a violência diária onde os corpos são marcados pela dor e submetidos a crueldades inimagináveis.

Rua é lugar de dor, de violência, onde a face cruel do ser humano é liberada. Rua é espaço de vida, mas também é espaço de morte, principalmente dos mais pobres, dos que estão em situação de rua que morrem pelo frio, pela fome, pela violência gratuita e pelo fogo que queima a carne, a vida e a esperança. (ANDRADE, 2019, p. 19).

Na rua impera a superioridades masculina que coloca as mulheres em posição de subordinação. Homens transformam mulheres em objeto de disputa que tem o sexo como prêmio. Seus copos passam a não lhes pertencer e seus filhos são entregues ao mundo.

Estando em situação de rua crianças e adolescentes passam e viver outra realidade, formam grupos, dividem tarefas onde o masculino e o feminino se dividem. O machismo existente nas relações de sociabilidade não deve ser compreendido de forma simplista ou caracterizado como crime, sem que antes todos os significantes sejam considerados. Nas violências existentes na rua há mais culpados do que inocentes e os maiores estão em posições sociais, políticas e econômicas bem distantes das ruas. A rua nos mostra o lado cruel da violência materializada na pobreza. 0 estar em situação de rua é, principalmente, fruto da pobreza e da carência de políticas públicas; é fruto do desgoverno. 


\section{REFERÊNCIAS}

ANDRADE, F. S. Crianças e adolescentes em situação de rua no Brasil:

Táticas de sobrevivência e ocupação do espaço público urbano. Jundiaí: Paco Editorial, 2019.

ANDRADE, F. S. Crianças e adolescentes em situação de rua: ocupação e domínio do espaço público urbano. 2014. Tese (Doutorado em Educação) - Programa de Pós Graduação em Educação, Universidade Federal de Mato Grosso, p. 167. 2014.

ANDRADE, F. S. Cotidiano, trajetórias e políticas públicas: crianças e adolescentes em situação de rua em Vitória da Conquista, Bahia (19972007). 2008. Dissertação (Mestrado em Ciências Sociais) - Programa de Pós Graduação em Ciências Sociais, Pontifícia Universidade Católica de São Paulo, p. 160. 2008.

BONETTI, A. L. Texto 3 - Desigualdade de gênero. In: JUNIOR, J. G. S.; APOSTOLOVA, B. S.; FONSECA, L. G. D. (orgs.). Introdução crítica ao direito das mulheres. Brasília: CEAD, FUB, 2011.

BRASIL. Lei Federal n. 8069, de 13 de julho de 1990. Estatuto da Criança e do Adolescente. Diário Oficial [da] República Federativa do Brasil. Brasília, DF, 14 jul. 1990.

CASTAÑEDA, M. 0 machismo invisível. São Paulo: A Girafa Editora, 2006.

CHAUÍ, M. Participando do debate sobre mulher e violência. In: CHAUÍ, M.; CARDOSO, R.; PAOLI, M. C. (org.). Perspectivas antropológicas da mulher: sobre mulher e violência. Rio de Janeiro: Zahar, 1984, p. 190 206.

FEFFERMANN, M. Vidas arriscadas: o cotidiano dos jovens trabalhadores do tráfico. Petrópolis: Vozes, 2006.

FREIRE, P. Pedagogia da indignação: cartas pedagógicas e outros escritos. São Paulo: Editora UNESP, 2000.

GREGORI, Maria Filomena. Viração: Experiências de Meninos nas Ruas. São Paulo: Companhia das Letras, 2000.

KOSMINSKY, E. V. Internados - Os desafios do Estado Padrasto. In: MARTINS, J. S. (coord.). O Massacre dos Inocentes: A criança sem infância no Brasil. São Paulo: Hucitec, 1993, p. 155 - 180.

JENKINS, K. A História Repensada. 3. ed. São Paulo: Contexto, 2007.

LEITE, L. C. Meninos de Rua: A infância excluída no Brasil. São Paulo: Atual, 2001. 
MERLEAU-PONTY, M. As aventuras da dialética. São Paulo: Martins Fontes, 2006.

MERLEAU-PONTY, M. Fenomenologia da percepção. 4. ed. São Paulo:

Martins Fontes, 2011.

PAIS, J. M. Vida cotidiana: enigmas e revelações. São Paulo: Cortez, 2003.

SWAIN, T. N. Texto 2 - Pequena introdução aos feminismos. In: JUNIOR, J. G. S.; APOSTOLOVA, B. S.; FONSECA, L. G. D. (orgs.). Introdução crítica ao direito das mulheres. Brasília: CEAD, FUB, 2011. 